Document downloaded from:

http://hdl.handle.net/10251/36563

This paper must be cited as:

Mitsuuchi Tashima, M.; Soriano Martinez, L.; Monzó Balbuena, JM.; Borrachero Rosado, MV.; Paya Bernabeu, JJ. (2013). novel geopolymeric material cured at room temperature. Advances in Applied Ceramics. 112:179-183. doi:10.1179/1743676112Y.0000000056.

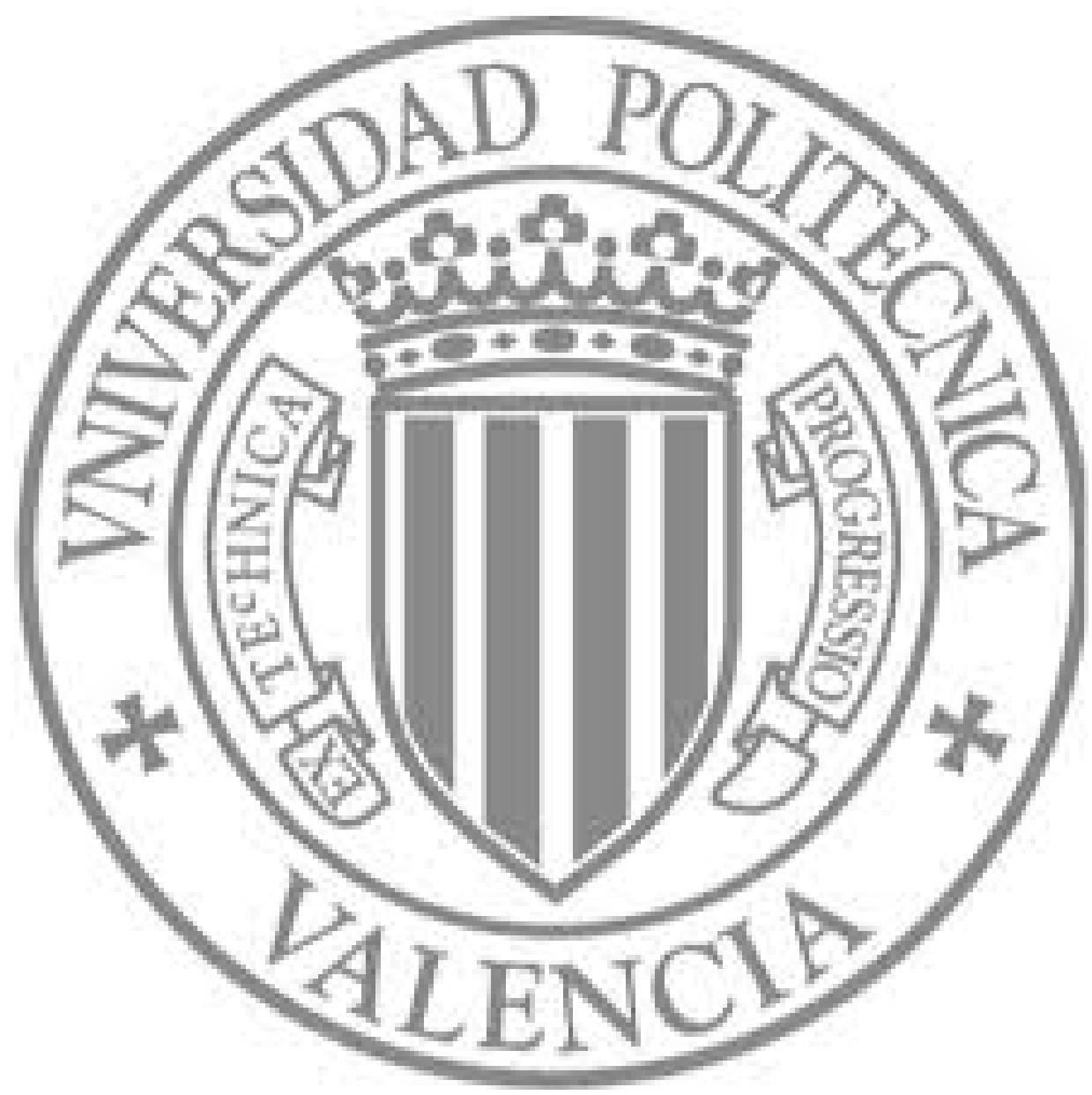

The final publication is available at

http://dx.doi.org/10.1179/1743676112Y.0000000056

Copyright Maney Publishing 


\title{
Novel geopolymeric material cured at room temperature
}

\author{
M.M. Tashima, L. Soriano, J. Monzó, M.V. Borrachero, J. Payá* \\ maumitta@hotmail.com, lousomar@upvnet.upv.es, jmmonzo@cst.upv.es, vborrachero@cst.upv.es, \\ jjpaya@cst.upv.es \\ Instituto de Ciencia y Tecnología del Hormigón - ICITECH. Universitat Politècnica de València. \\ Camino de Vera s/n, Edificio 4G, 46022 Valencia. Spain. \\ *Corresponding author: jjpaya@cst.upv.es
}

\begin{abstract}
Alkali activated binders are a new class of binding material with comparable or enhanced performance to Portland cement. These binding materials are obtained by a chemical reaction between an alumino-silicate material and a highly alkaline solution. In most cases, the setting-hardening process of this binder is performed at high curing temperatures. In this paper, alkali activated mortars based on Vitreous Calcium Aluminosilicate (VCAS) cured at room temperature are evaluated. Mechanical strength development and microstructural analysis (scanning electron microscopy, thermogravimetric analysis, X-ray diffraction and mercury intrusion porosimetry) of these materials are performed. Mortars yielded compressive strength around $89 \mathrm{MPa}$ after 360 days. This is the first time that VCAS is used as alumino-silicate source material in the production of alkali activated mortars cured at room temperature.
\end{abstract}

Keywords: alkali activated binder, VCAS, room temperature, mechanical strength.

\section{Introduction}

Alkali activated materials are a new class of binding material which presents several advantages over Portland cement (high compressive strength, better fire resistance, good durability and low production cost). However, the most important factor that drives its use as alternative cement is its lower $\mathrm{CO}_{2}$ emission compared to Portland cement. Depending on the alumino-silicate material, a reduction up to $80 \%$ in $\mathrm{CO}_{2}$ emission can be reached (Duxson et al., 2007; van Deventer et al., 2010).

Alkali activated binders, also known as geopolymers, are generated by a polymerization reaction between an alumino-silicate source material (in amorphous state) and a highly alkaline solution, under controlled curing conditions.

Alumino-silicate source materials commonly used in alkali activated systems are metakaolin (Davidovits, 1994), slag (Fernández-Jiménez et al., 1999) and fly ashes (Palomo et al., 1999; Provis et al, 2009). Nevertheless, other byproducts such as spent FCC catalyst, hydrated-carbonated cement, tungsten mine waste, natural pozzolans have been used in the production of alkali activated binders (Tashima et al., 2012a, Payá et al., 2012, Pacheco-Torgal et al. 2008, Xu and van Deventer, 2000).

Currently, the alkaline solutions are prepared by mixing $\mathrm{NaOH}, \mathrm{KOH}$, and/or waterglass $\left(\mathrm{Na}_{2} \mathrm{SiO}_{3}\right)$ with the required amount of water. However, other alkaline activators can also be used: $\mathrm{K}_{2} \mathrm{CO}_{3}$, $\mathrm{Na}_{2} \mathrm{SO}_{4}$ and $\mathrm{Na}_{2} \mathrm{CO}_{3}$.

The curing conditions play a very important role on the final properties of alkali activated binder. Normally, these binders are cured at $40-80{ }^{\circ} \mathrm{C}$ for 2-72 hours in dry or steam curing conditions. The high curing temperature required is one of the factors that inhibit the use of alkali activated systems in large scale.

In the literature, some researches on alkali activated binders cured at room temperature are reported (Shi and Quian, 2000; Temuujin et al, 2009). Most of them are related to the use of blast furnace slag as raw material (Bakharev et al., 1999). The ability of setting and hardening at room temperature is related to the hydraulic nature of this material. Shi and Quian (2000) reported mortars based on alkali activation of slag with 160 $\mathrm{MPa}$ in compressive strength cured at room temperature after 28 days.

The use of binary systems combining slags with other alumino-silicate source materials is also reported in several papers (Gordon et al, 2011; Escalante-García et al., 2006; Pan et al., 2002; Puertas and Fernández-Jiménez, 2003; Kumar et al., 2010). Bernal et al. (2011) reported some studies about alkali activated binders prepared with slag-metakaolin blends. These mortars show mechanical strength of at least $40 \mathrm{MPa}$ after 7 days of curing at $27^{\circ} \mathrm{C}$.

Temuujin et al. (2009) performed an investigation using an ASTM type $\mathrm{F}$ fly ash as alumino-silicate material. The geopolymeric pastes yielded a compressive strength of 25-45 MPa, depending on the particle size distribution of fly ash.

Otherwise, Somna et al. (2011) studied the influence of $\mathrm{NaOH}$ concentration of alkali activated fly ash pastes cured at room temperature. The compressive strength for these pastes was in the range 2-16 MPa for original fly ash (OFA) and 2-26 MPa for ground fly ash (GFA).

Lampris et al. (2009) reported a study of silt derived from washing aggregates in the geopolymerization process. The optimum 
compressive strength achieved (specimens were pressed in a steel mould at $24 \mathrm{MPa}$ ) was $18.7 \mathrm{MPa}$ for silt geopolymer specimens cured at room temperature after 7 days.

The use of Vitreous Calcium Aluminosilicate (VCAS) in alkali activated systems was first time reported by Tashima et al. (2009). The authors studied the influence of $\mathrm{NaOH}$ concentration on geopolymeric mortars cured at $65{ }^{\circ} \mathrm{C}$ after three days, yielding compressive strength values around $77 \mathrm{MPa}$ for $10 \mathrm{~mol} . \mathrm{kg}^{-1} \mathrm{NaOH}$ solution. Recently, Tashima et al. (2012b) studied the effect of curing time for 10 mol. $\mathrm{kg}^{-1} \mathrm{NaOH}$ alkali activated mortars, demonstrating that 3 hours at $65^{\circ} \mathrm{C}$ is the optimum curing time for this curing temperature.

VCAS is a new supplementary cementitious material which has been successfully used in Portland cement binders (Hossain and Shirazi, 2008; Neithalath et al., 2009). VCAS is a high reactivity pozzolanic material and this product is manufactured by heating glass fiber waste to a molten state which is then solidified by rapid cooling (quenching), processed and ground to get a fine white powder. With this technology, the glass industry can prevent the landfilling of about 200,000 tons of waste glass fiber annually, along with its associated negative environmental impact. In this paper, VCAS is used as alumino-silicate source material in the production of alkali activated systems cured at room temperature. This is the first time that VCAS is used as alumino-silicate source material in the production of geopolymers cured at room temperature.

\section{Experimental}

VCAS was supplied by Vitrominerals. The chemical composition of VCAS, determined by means of XRF, is listed in Table 1.

Table 1. Chemical composition of VCAS (\%, by weight).

\begin{tabular}{cc}
\hline oxide (\%) & VCAS \\
\hline $\mathrm{SiO}_{2}$ & 57.9 \\
$\mathrm{Al}_{2} \mathrm{O}_{3}$ & 12.92 \\
$\mathrm{CaO}$ & 23.51 \\
$\mathrm{Na}_{2} \mathrm{O}$ & 0.74 \\
$\mathrm{MgO}$ & 2.88 \\
$\mathrm{~K}_{2} \mathrm{O}$ & 0.13 \\
$\mathrm{Fe}_{2} \mathrm{O}_{3}$ & 0.47 \\
others & 1.45 \\
\hline
\end{tabular}

VCAS presents high $\mathrm{SiO}_{2}-\mathrm{Al}_{2} \mathrm{O}_{3}-\mathrm{CaO}$ content and an amorphous structure determined by X-ray diffraction. Besides its high $\mathrm{CaO}$ content, VCAS does not have any hydraulic behaviour (Neithalath et al., 2009).

Figure 1 presents some SEM micrographs of VCAS sample. At the top, a general view of particle size distribution of VCAS can be observed. All VCAS particles have a diameter size smaller than
$60 \mu \mathrm{m}$. From a laser granulometric analysis, a mean particle size of $12 \mu \mathrm{m}$ was found, with $90 \%$ of particles below of $26 \mu \mathrm{m}$. Also in Figure 1 (bottom), micrograph shows a detailed aspect of VCAS particles. The irregular form, a dense and sharp structure are the most important characteristics of VCAS particles.

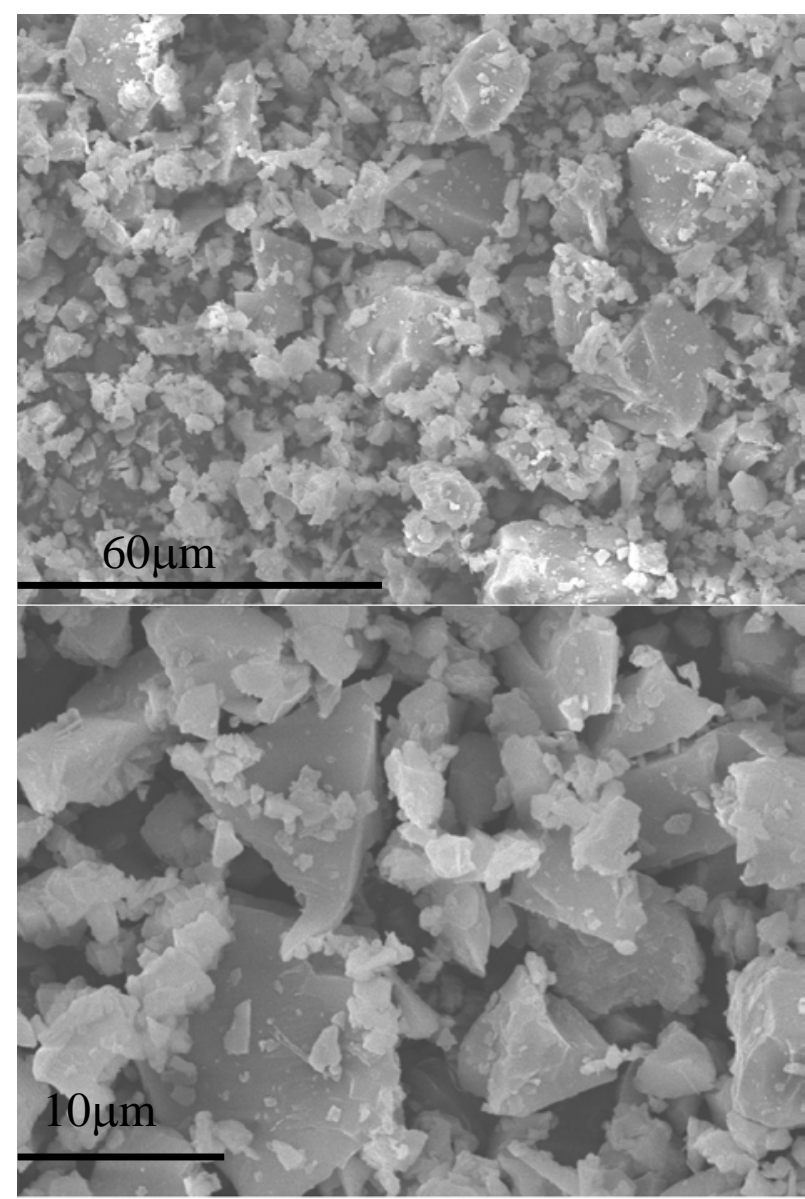

Figure 1. SEM micrographs for VCAS sample.

In the alkali activation of VCAS cured at room temperature, sodium hydroxide (98\% purity) supplied by PANREAC S.A. and waterglass (28\% $\mathrm{SiO}_{2} ; 8 \% \mathrm{Na}_{2} \mathrm{O} ; 64 \% \mathrm{H}_{2} \mathrm{O}$ ) from MERCK were used in the preparation of the alkaline activator solution.

It is important to state that geopolymers based on VCAS activated with $\mathrm{NaOH}$ solution did not harden at room temperature (Tashima et al., 2009). In this case, the use of waterglass is necessary because the ability to set/harden at room temperature depends on the $\mathrm{SiO}_{2} / \mathrm{Na}_{2} \mathrm{O}$ molar ratio of the alkaline solution.

In order to get setting at room temperature, alkali activation of VCAS was achieved with $\mathrm{a}_{2} \mathrm{O} / \mathrm{Na}_{2} \mathrm{O}$ molar ratio of 11.11 and $\mathrm{SiO}_{2} / \mathrm{Na}_{2} \mathrm{O}$ molar ratio of 5.0. For mortars specimens, the VCAS:sand ratio was fixed in 1:3 and the water/VCAS mass ratio was 0.45 . A set of mortars were cured at room temperature $\left(20^{\circ} \mathrm{C}, \mathrm{RH}>95 \%\right)$, and tested after 28 , 91 and 360 days, and another set was cured at 65 ${ }^{\circ} \mathrm{C}(\mathrm{RH}>95 \%)$ for 3 days. Alkali activated pastes (without sand) with similar dosage were analyzed 
by TGA, XRD and SEM to assess the microstructure of the geopolymer formed.

Mechanical strength testing was carried out on alkali activated mortars for 28, 91 and 360 days of curing at room temperature. For that, a universal testing machine was used and tests were performed according to UNE-EN 196-1 standard.

Mercury Intrusion Porosimeter (MIP) using Micromeritics Instrument Corporation was used to evaluate the porosity of alkali activated VCAS mortars. In this case, the intrusion pressure applied was in the range of $13782 \mathrm{~Pa}$ until 227.4 $\mathrm{MPa}$.

Mineralogical phase data obtained for alkali activated VCAS were collected using a Philips diffractometer PW1710 with $\mathrm{Cu}$ Ka radiation, under routine conditions of $40 \mathrm{Kv}$ and $20 \mathrm{~mA}$, from $5-55^{\circ}$ $(2 \Theta)$.

Thermogravimetric analysis (TGA) was performed in a TGA 850 Mettler-Toledo thermobalance under nitrogen atmosphere, in pinholed-aluminium sealed crucibles, with a heating rate of $10^{\circ} \mathrm{C} \mathrm{min}^{-1}$, from $35^{\circ} \mathrm{C}$ until $600^{\circ} \mathrm{C}$.

Microstructural analyses were carried out by means of Scanning Electron Microscopy (SEM), using a JEOL JSM-6300.

\section{Results and discussion}

Mechanical properties of alkali activated (AAVCAS) mortars cured at room temperature are presented in Table 2. The mechanical development showed the existence of a reaction between the amorphous phase of VCAS $\left(\mathrm{SiO}_{2}-\mathrm{Al}_{2} \mathrm{O}_{3}-\mathrm{CaO}\right)$ and the alkaline solution, yielding a stable matrix.

Compressive strength about 38.6 MPa was measured for alkali activated mortar cured at room temperature for 28 days. After 91 curing days, alkali activated VCAS yielded compressive strength about $78.5 \mathrm{MPa}$. It represents an increase up to $103.4 \%$ comparing to mortars cured at 28 days. The obtained result shows a slow reaction rate for alkali activated VCAS mortars cured at room temperature.

After 360 days, geopolymeric mortars based on VCAS yielded compressive strength values about 89.5 $\mathrm{MPa}$, indicating that the reaction also took place for long curing time.

Table 2. Mechanical properties of alkali activated mortars cured at room temperature.

\begin{tabular}{ccc}
\hline & Flexural strength $(\mathrm{MPa})$ & Compressive strength $(\mathrm{MPa})$ \\
\hline 28d & $3.1 \pm 0.1$ & $38.6 \pm 0.7$ \\
91d & $6.8 \pm 0.4$ & $78.5 \pm 1.4$ \\
360d & $11.4 \pm 0.4$ & $89.5 \pm 6.2$ \\
\hline
\end{tabular}

Nevertheless, alkali activated mortars based on VCAS cured at room temperature yielded similar or even higher values of compressive strength for a long period of curing. The compressive strength was 78.5 MPa for 91 days and $89.5 \mathrm{MPa}$ for 360 days. The results suggested that the high curing temperature accelerates the geopolymerization reaction. However, mortars cured at room temperature yield higher compressive strength for long curing times than mortars cured at high temperature.

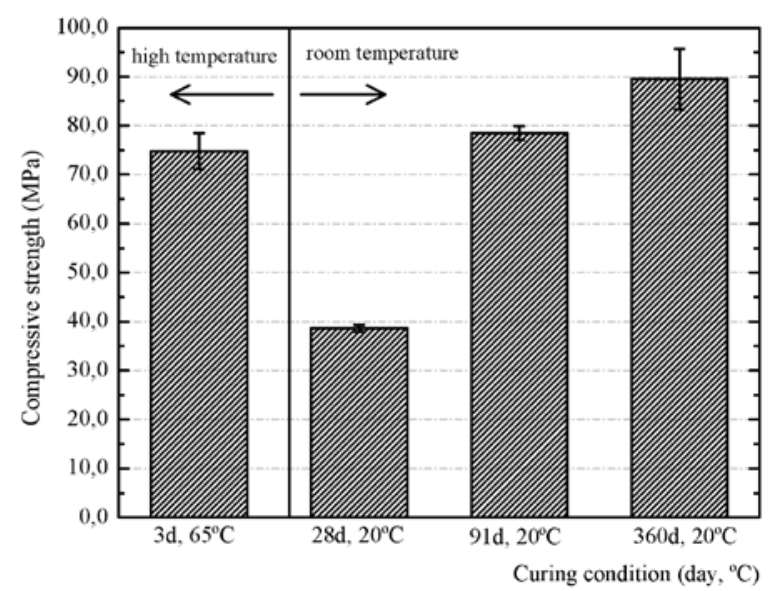

Figure 2. Comparison of compressive strength of mortars cured at room temperature (different curing ages) and the mortar cured at $65^{\circ} \mathrm{C}$ for 3 days.

The total porosity of AA-VCAS mortars cured for 28 and 360 days were analysed by means of mercury intrusion porosimetry (MIP test). The total porosity obtained was $8.65 \%$ and $7.21 \%$ for AAVCAS mortars cured for 28 and 360 days, respectively. It can be noticed a slight reduction in the total porosity caused by the progress of geopolymerization reaction that form amorphous gels which contributes to the densification of the alkali activated matrix.

In Figure 3, pore size range distributions for both mortars cured at 28 and 360 days are depicted.

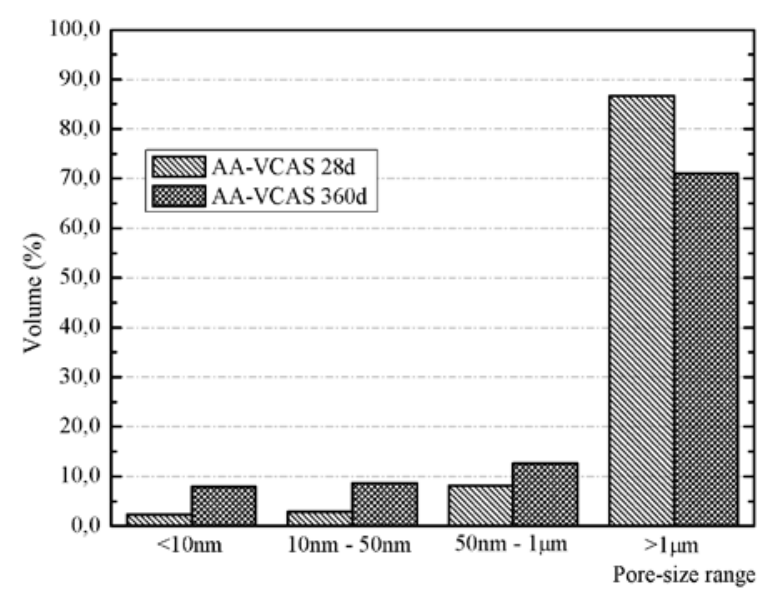

Figure 3. Pore-size range for AA-VCAS cured at room temperature for 28 and 360 days.

As it can be observed, AA-VCAS mortars present a high amount of pores greater than $1 \mu \mathrm{m}$. According to Metha and Monteiro (1994), this pore size range is classified as large capillaries and/or entrained 
air, which are probably formed due to excess of water in the sample.

The curing from 28 to 360 days produced a significant decrease in this pore-size range, reducing from $86.7 \%$ to $71.0 \%$. Obviously, large pores are being reduced during the geopolymerization in the 28-360 days period, and the relative percentage of medium capillaries (10 $\mathrm{nm}-1 \mu \mathrm{m})$, as well as the gel pores, are increased. Thus, the percentage of volume related to gel pores (diameter less than 10nm) was increased from 2.32 to $7.89 \%$. The slight reduction in the large capillaries and the reduction on total porosity contributed to the densification of matrix and, consequently, to the increase in the compressive strength of mortars.

Microstructural analyses of alkali activated pastes were carried out in order to study the development of the geopolymeric reaction. Thermogravimetric analyses of pastes were performed for 28, 91 and 360 curing days at room temperature. Figure 4 shows DTG curves for AA-VCAS pastes. The total weight loss observed in the range of $35-600^{\circ} \mathrm{C}$ were $15.83 \%, 17.58 \%$ and $17.17 \%$ for 28,91 and 360 days, respectively. The increase in total weight loss for these pastes are related to the formation of geopolymeric products. The broad band centered at $135-145^{\circ} \mathrm{C}$ was also reported by Bernal et al. (2010), indicating the descomposition of geopolymeric gel formed in the alkali activation reaction. The DTG curves for pastes cured at room temperature were similar to those found for paste cured at $65^{\circ} \mathrm{C}$ for 3 days, suggesting the similarity of the produced binding matrix.

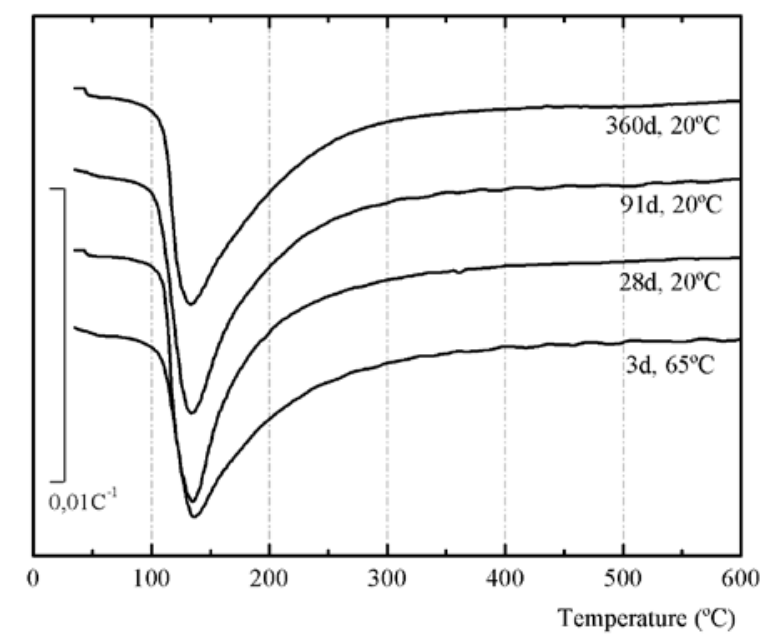

Figure 4. DTG curves for AA-VCAS pastes cured at $65^{\circ} \mathrm{C}$ for 3 days and at room temperature for 28,91 and 360 days.

XRD patterns were analyzed for alkali activated VCAS pastes cured at room temperature. Figure 5 compares the X-ray diffraction patterns of VCAS sample and alkali activated VCAS pastes. VCAS is a calcium aluminosilicate material, amorphous in nature. It is confirmed by means of the baseline deviation observed in the $2 \Theta$ range of $15-35^{\circ}$. The alkali activated binders formed by mixing VCAS and a high alkaline solution yield an amorphous XRD pattern.

No evidences of evolution in the XRD pattern were observed when diffractograms for 28 and 91 days are compared. Usually, the formation of crystalline phases such as zeolite structures are easily detected for alkali activated systems cured at high temperatures and for a long curing time (Provis et al., 2005). In our case, the presence of crystalline phases in the XRD patterns was not found. Adding to this, the presence of high amount of soluble silicate $\left(9.8 \%\right.$ of $\mathrm{SiO}_{2}$ respect to VCAS) prevents the formation of crystalline phases.

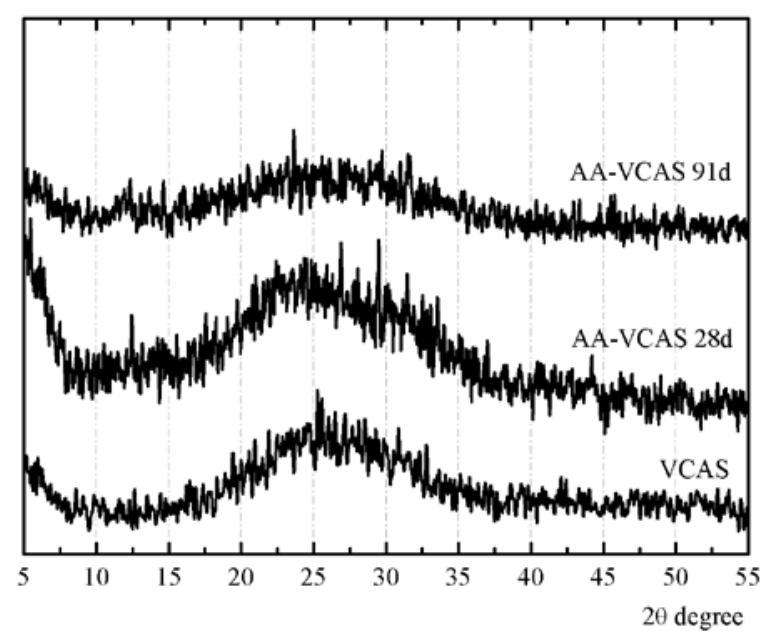

Figure 5. XRD patterns for VCAS and AA-VCAS cured at room temperature.

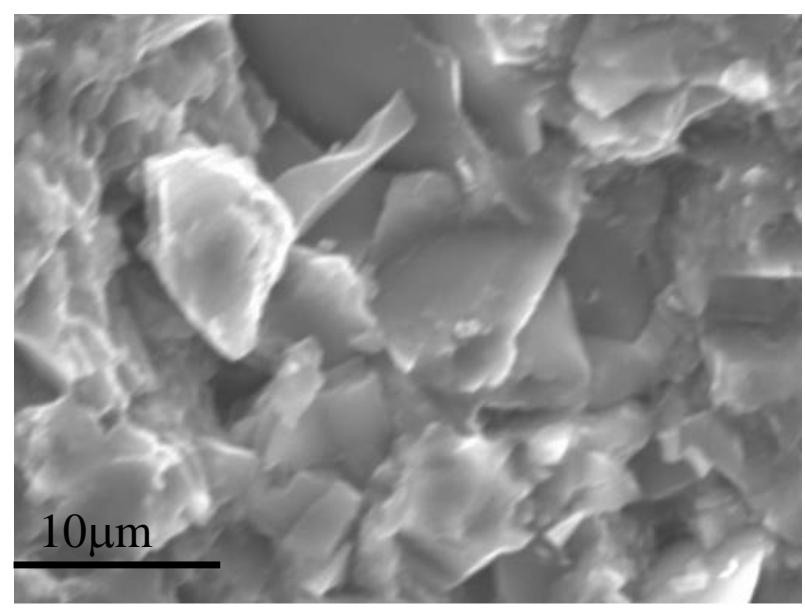




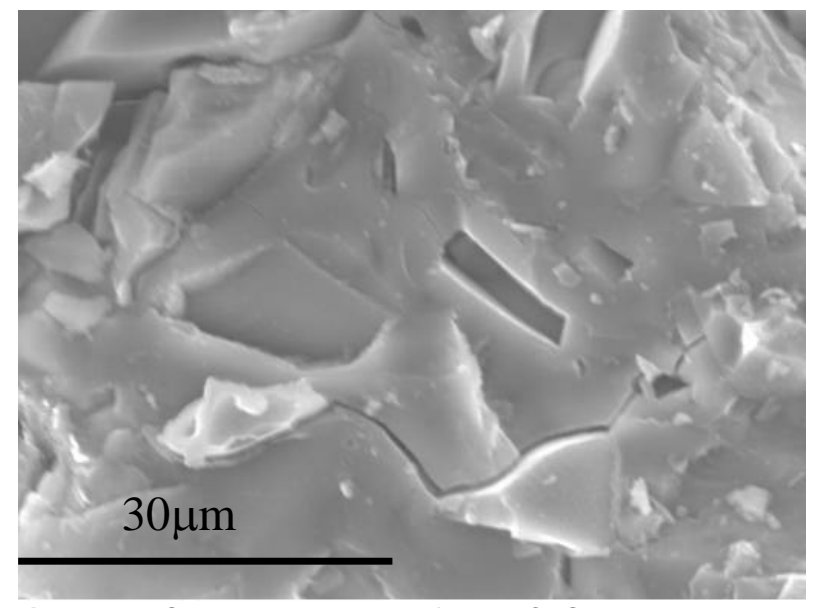

Figure 6. SEM micrographs of AA-VCAS cured at room temperature: 28 days (top) and 91 days (bottom).

In Figure 6, some SEM micrographs of AA-VCAS pastes cured at room temperature for different curing times are shown. At the top, the microstructure of a paste cured for 28 days is observed. The presence of unreacted or partially reacted particles of VCAS is evident (particles with sharp aspect). These particles are embedded in the geopolymeric matrix which presents an amorphous structure.

The bottom micrograph shows a very dense and compact geopolymeric matrix. Some micro cracks are identified in the paste, probably due to a shrinkage process or due to the preparation of the studied sample. It is possible to observe that almost all VCAS particles have reacted in the geopolymeric matrix due to the long curing time.

\section{Conclusions}

VCAS is a byproduct from glass fibre manufacturing, which provides good properties to be applied as raw material in geopolymeric binders cured at room temperature. Alkali activated mortars based on VCAS generates a stable, dense and a high compressive strength binding material with $78.5 \mathrm{MPa}$ and $89.5 \mathrm{MPa}$, after 91 and 360 days of curing, respectively. The microstructure of the AA-VCAS is amorphous and no crystalline phases were detected in the XRD analysis.

\section{Acknowledgements}

To the Ministerio de Ciencia e Innovación (MICINN) of the Spanish Government (BIA201126947 project). To Vitrominerals company for supplying VCAS samples.

\section{References}

Bakharev, T., Sanjayan J. G., y Cheng Y-Bing. 1999. Alkali activation of Australian slag cements. Cement and Concrete Research 29(1): 113-120. Bernal, S.A., de Gutierrez, R., Provis, J.L., Rose, V. 2010. Effect of silicate modulus and metakaolin incorporation on the carbonation of alkali silicate- activated slags. Cement and Concrete Research 40(6): 898-907.

Bernal, S. A., J. Provis, Volker R., y Mejía, R. G.. 2011. Evolution of binder structure in sodium silicate-activated slag-metakaolin blends. Cement and Concrete Composites 33(1): 46-54.

Davidovits, J. 1994. Geopolymer: Man-made rock geosynthesis and the resulting development of very early high strength cement. Journal of Materials Education 16(2): 91-139.

van Deventer, J.S.J., Provis J.L., Duxson P., Brice, D. 2010. Chemical Research and Climate Change as Drivers in the Commercial Adoption of Alkali Activated Materials. Waste and Biomass Valorization 1(1): 145-155.

Duxson, P., Provis J.L., Lukey, G.C., van Deventer, J.S.J. 2007. The role of inorganic polymer technology in the development of green concrete. Cement and Concrete Research 37(12): 15901597.

Escalante-Garcia,J.I., Campos-Venegas, K., Gorokhovsky, A., et al. 2006. Cementitious composites of pulverised fuel ash and blast furnace slag activated by sodium silicate: effect of $\mathrm{Na}_{2} \mathrm{O}$ concentration and modulus. Advances in Applied Ceramics 105(4): 201-208.

Fernández-Jiménez, A., Palomo, J.G., Puertas, F. 1999. Alkali-activated slag mortars: Mechanical strength behaviour. Cement and Concrete Research 29(8): 1313-1321.

Fernández-Jiménez, A., Puertas, F. 1997. Alkaliactivated slag cements: Kinetic studies. Cement and Concrete Research 27(3): 359-368.

Gordon, L.E., Provis, J.L., van Deventer, J.S.J. 2010. Durability of fly ash/GGBFS based geopolymers exposed to carbon capture solvents. Advances in Applied Ceramics 10(8): 446-452.

Hossain, A., Shirazi, S.A. 2008. Properties of concrete containing vitreous calcium aluminosilicate pozzolan. Journal of the transportation research board: 32-38.

Kumar, S., Kumar, R., Mehrotra, S. 2010. Influence of granulated blast furnace slag on the reaction, structure and properties of fly ash based geopolymer. Journal of Materials Science 45(3): 607-615.

Lampris, C., Lupo R., Cheeseman, C.R. 2009. Geopolymerisation of silt generated from construction and demolition waste washing plants. Waste Management 29(1): 368-373.

Metha, P.K., Monteiro, P.J.M. 1994. Concrete: Structure, Properties and Materials. Pini, São Paulo (in Portuguese).

Neithalath, N., Persun J., Hossain, A. 2009. Hydration in high-performance cementitious systems containing vitreous calcium aluminosilicate or silica fume. Cement and Concrete Research 39(6): 473-481.

Pacheco-Torgal, F., Castro-Gomes, J., Jalali, S. 2008. Properties of tungsten mine waste geopolymeric binder. Construction and Building Materials 22(6): 1201-1211. 
Palacios, M., Houst, Y.F., Bowen, P., Puertas, F. 2009. Adsorption of superplasticizer admixtures on alkali-activated slag pastes. Cement and Concrete Research 39(8): 670-677.

Palomo, A., Grutzeck, M.W, Blanco, M. T. 1999. Alkali-activated fly ashes: A cement for the future. Cement and Concrete Research 29 (8): 13231329.

Pan, Z., Cheng, L., Lu, Y., Yang, N. 2002. Hydration products of alkali-activated slag-red mud cementitious material. Cement and Concrete Research 32(3): 357-362.

Payá, J., Borrachero, M.V., Monzó, J., Soriano, L., Tashima, M.M. 2012. A new geopolymeric binder from hydrated-carbonated cement. Materials Letters 74: 223-225.

Provis, J.L., Lukey, G.C., van Deventer, J.S.J. 2005. Do Geopolymers Actually Contain Nanocrystalline Zeolites? A Reexamination of Existing Results. Chemistry of Materials 17(12): 3075-3085.

Provis, J.L., Yong, C.Z., Duxson, P. van Deventer, J.S.J. 2009. Correlating mechanical and thermal properties of sodium silicate-fly ash geopolymers. Colloids and Surfaces A: Physicochemical and Engineering Aspects 336 (1-3): 57-63.

Puertas, F. Fernández-Jiménez, A. 2003. Mineralogical and microstructural characterization of alkali-activated fly ash/slag pastes. Cement and Concrete Composites 25(3): 287-292.

Puertas, F., M. Palacios, A. Gil-Maroto, T. Vázquez. 2009. Alkali-aggregate behaviour of alkali-activated slag mortars: Effect of aggregate type. Cement and Concrete Composites 31(5): 277-284.

Puertas, F., Fernández-Jiménez, A. 2003. Mineralogical and microstructural characterisation of alkali-activated fly ash/slag pastes. Cement and Concrete Composites 25(3): 287-292.

Shi, C., Qian, J. 2000. High performance cementing materials from industrial slags - a review. Resources, Conservation and Recycling 29 (3): 195-207.

Somna, K., Jaturapitakkul, P., Chidaprasirt, P. 2011. NaOH-activated ground fly ash geopolymer cured at ambient temperature. Fuel 90(6): 21182124.

Tashima, M.M., Borrachero, M.V., Monzó, J., Soriano, L., Payá, J. 2009. Nuevos materiales compuestos con matriz activadas alcalinamente. In: COMATCOMP09, VIII Congreso Nacional de Materiales Compuestos, San Sebastián: 421-424. Tashima, M.M., Akasaki, J.L., Castaldelli, V.N., Soriano, L., Monzó, J., Payá, J., Borrachero, M.V. 2012a. New geopolymeric binder based on fluid catalytic cracking catalyst residue (FCC). Materials Letters 80: 50-52.

Tashima, M.M., Soriano, L., Borrachero, M.V., Monzó, J., Payá, J. 2012b. Effect of curing time on the microstructure and mechanical strength development of alkali activated binders based on Vitreous Calcium Aluminosilicate (VCAS). Bulletin of Materials Science. Accepted manuscript.
Temuujin, J., Williams, R.P., van Riessen, A. 2009. Effect of mechanical activation of fly ash on the properties of geopolymer cured at ambient temperature. Journal of Materials Processing Technology 209(12-13): 5276-5280.

$\mathrm{Xu}, \quad$ H., van Deventer, J.S.J. 2000. The geopolymerization of alumino-silicate materials. International Journal of Mining Process 59(3): 247266. 